\title{
Development and validation of UV spectroscopic methods for simultaneous estimation of ciprofloxacin and tinidazole in tablet formulation
}

\author{
*Sowjanya Gummadi ${ }^{1}$, Devi Thota ${ }^{1}$, Sri Valli Varri ${ }^{1}$, Pratyusha Vaddi ${ }^{1}$, Venkata Lakshmi Narasimha Seshagiri Rao Jillella ${ }^{2}$ \\ ${ }^{1}$ GITAM Institute of Pharmacy, GITAM University, Visakhapatnam-530045, India \\ ${ }^{2}$ College of Pharmaceutical Sciences, Andhra University, Visakhapatnam-530003, India
}

\begin{abstract}
Two simple, accurate, precise, reproducible and economical UV spectroscopic methods (A \& B) for simultaneous estimation of Ciprofloxacin and Tinidazole in tablet dosage form have been developed. Method A employs solving of simultaneous equations based on the measurement of absorbance at two wavelengths, $271 \mathrm{~nm}$ and $318 \mathrm{~nm}$ which are the $\lambda_{\max }$ values of Ciprofloxacin and Tinidazole respectively in phosphate buffer ( $\mathrm{pH}$ 6.8). Method $\mathrm{B}$ is based on the principle of Q-Analysis where in the absorbance was measured at $292 \mathrm{~nm}$ (iso-absorptive point) and $271 \mathrm{~nm}\left(\lambda_{\max }\right.$ of Ciprofloxacin)in phosphate buffer ( $\mathrm{pH}$ 6.8). Ciprofloxacin and Tinidazole shows linearity at all the selected wavelengths and obeys Beer's law in the concentration range of $10-35 \mu \mathrm{g} / \mathrm{mL}$ and $10-80 \mu \mathrm{g} / \mathrm{mL}$ respectively. Recovery studies for Ciprofloxacin and Tinidazole were performed and the percentage recovery for both the drugs was obtained in the range of 98.1-99.7\% (Method A) and 98.0-100.4\% (Method B) confirming the accuracy of the proposed method. Both the methods showed good reproducibility and recovery with \%RSD less than 2 . Statistical validation of the data shows that the proposed methods can be successfully applied for the routine analysis of drugs in commercial tablets.
\end{abstract}

Key Words: Ciprofloxacin, tinidazole, simultaneous equations, Q-Analysis, iso-absorptive point, buffer, molar absorptivity.

\section{INTRODUCTION}

Ciprofloxacin (CPX) is a fluorinated quinolone antibacterial which is chemically 1-cyclopropyl-6fluoro-4-oxo-7-(piperazin-1-yl)-quinoline-3-carboxylic acid (The Merck Index, 2006). Ciprofloxacin is a broad spectrum antibiotic active against both Gram-positive and Gram-negative bacteria. It functions by inhibiting DNA gyrase, a type II topoisomerase, and topoisomerase IV enzymes necessary to separate bacterial DNA, thereby inhibiting cell division (Drlica and Zhao, 1997). Tinidazole (TNZ) is chemically 1-(2-ethylsulfonylethyl)-2-methyl-5-nitro-imidazole (The Merck Index, 2006). It is active against both protozoa and obligate anaerobic bacteria. It damages DNA strands or inhibit DNA synthesis in microorganism.

\footnotetext{
*Corresponding Author:

Sowjanya Gummadi, Assistant Professor

GITAM Institute of Pharmacy, GITAM University

Rushikonda,Visakhapatnam-530045

India

E-mail: tatinenisowjanya@rediffmail.com

Contact No.: +91-9989640339
}

Literature survey revealed that various analytical methods such as UV spectroscopy (Bombale et al., 1997; Sharma et al., 2011), HPLC (Bhatia et al., 1999), pulsepolarography (Salvi and Sathe, 2010) have been reported for the simultaneous estimation of both the drugs. This study is useful because these two drugs are commonly administered simultaneously. The UV spectrophotometric analysis is often preferred in quality control testing and ordinary laboratories due to its broader availability, suitability and ease of use (Nijhu et al., 2011). The aim of the present investigation is to develop a simple, sensitive and reproducible UV Spectrophotometric method for analysis of CPX and TNZ in a combined tablet dosage form and hence an economical method was developed and validated according to the ICH guidelines. 


\section{MATERIAL AND METHODS}

\section{Instruments}

Absorbance measurements were made on Shimadzu $1800 \mathrm{UV} /$ Visible spectrophotometer with a pair of 10 $\mathrm{mm}$ matched quartz cells, Shimadzu digital balance for weighing and Cintex sonicatorwere used.

\section{Chemicals and reagents}

All chemicals were of analytical reagent grade and solutions were prepared with double distilled water. Ciprofloxacin and Tinidazole gift samples were obtained from Dr. Reddy's Laboratories, Hyderabad. Potassium dihydrogen ortho phosphate and Methanol were procured from E. Merck Co., Mumbai, India. Sodium hydroxide was purchased from Qualigen's. Combined tablets of CPX and TNZ (Ciplox-Tz, Ciprolet) were procured from the local pharmacy.

\section{Procedure}

Preparation of phosphate buffer ( $p H$ 6.8)

Accurately weigh about $0.896 \mathrm{gm}$ of $\mathrm{NaOH}, 6.804$ gm of $\mathrm{KH}_{2} \mathrm{PO}_{4}$, dissolve in distilled water and make up the volume to 1 Litre with distilled water.

\section{Preparation of stock solution $(1000 \mu \mathrm{g} / \mathrm{mL})$}

Accurately weighed quantity of pure Ciprofloxacin $(10 \mathrm{mg})$ and pure Tinidazole $(10 \mathrm{mg})$ were transferred into two separate $10 \mathrm{~mL}$ volumetric flasks, dissolved in methanol and made up the volume to $10 \mathrm{~mL}$ with the same solvent. The stock solution was sonicated for $2 \mathrm{~min}$.

\section{Preparation of working standard solution $(100 \mu \mathrm{g} / \mathrm{mL})$}

From the above stock solution $1 \mathrm{~mL}$ each of CPX and TNZ was taken,transferred to separate $10 \mathrm{~mL}$ volumetric flasks and the volume was made up to $10 \mathrm{~mL}$ with phosphate buffer.

\section{Simultaneous Equations Method (Method A)}

$10 \mu \mathrm{g} / \mathrm{mL}$ solutions of CPX and TNZ were prepared separately in phosphate buffer $(\mathrm{pH}$ 6.8) and the solutions were scanned against blank in the entire UV range to determine the $\lambda_{\max }$ values. Clear peaks were observed at $271 \mathrm{~nm}$ for CPX and $318 \mathrm{~nm}$ for TNZ. Hence these wavelengths were chosen as the $\lambda_{\max }$ values for each drug respectively(Fig 1).Standard solutions of CPX and TNZ in the concentration range of $10-35 \mu \mathrm{g} / \mathrm{mL}$ and $10-80 \mu \mathrm{g} / \mathrm{mL}$ respectively were prepared in phosphate buffer and the absorbance of these solutions was measured at

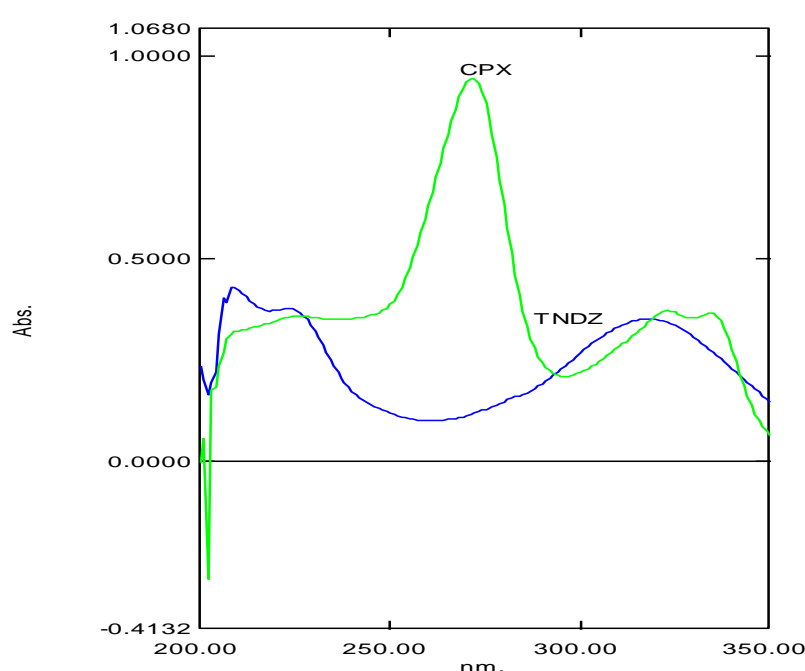

Figure 1: Overlay spectra of Ciprofloxacin and Tinidazole.

271nm and $318 \mathrm{~nm}$. Calibration curves were plotted to verify the Beer's law and the absorptivity values calculated at the respective wavelengths for both the drugs. Two simultaneous equations as below were formed using these absorptivity values, A (1\%, $1 \mathrm{~cm})$.

$A_{1}=924 b C_{x}+108 b C_{y}$

$\mathrm{A}_{2}=339 \mathrm{bc} \mathrm{c}_{\mathrm{x}}+367 \mathrm{bC}$

Where, $\mathrm{Cx}$ and $\mathrm{Cy}$ are the concentrations of CPX and TNZ measured in gm/100mLin sample solutions. A 1 and $A_{2}$ are the absorbances of mixture at selected wavelengths $271 \mathrm{~nm}$ and $318 \mathrm{~nm}$ respectively.

\section{Absorbance Ratio Method/ Q-Analysis (Method B)}

The absorbance ratio method is a modification of the simultaneous equation procedure. It depends on the property that for a substance, which obeys Beer's law at all wavelength, the ratio of absorbance at any two wavelengths is constant value independent of concentration or path length. E.g. two dilutions of the same substance give the same absorbance ratio $\mathrm{A}_{1}$ / $\mathrm{A}_{2}$. In the USP, this ratio is referred to as $\mathrm{Q}$ value. In the quantitative assay of two components in admixture by the absorbance ratio method, absorbances are measured at two wavelengths, one being the $\lambda_{\max }$ of one of the components $\left(\lambda_{2}\right)$ and the other being a wavelength of equal absorptivity of the two components $\left(\lambda_{1}\right)$, i.e., an iso-absorptive point (Beckett and Stenlake, 2005). A series of standard solutions of CPX and TNZ in the concentration range of $10-35 \mu \mathrm{g} / \mathrm{mL}$ and $10-80 \mu \mathrm{g} / \mathrm{mL}$ respectively were prepared in phosphate buffer and the absorbance of these solutions was measured at 292nm (iso-absorptive point) and $271 \mathrm{~nm}\left(\lambda_{\max }\right.$ of CPX) (Figure 1). Calibration 
Table 1: Absorptivity values (A 1\%, $1 \mathrm{~cm}$ ) of Ciprofloxacin (CPX) and Tinidazole (TNZ) for methods A \& B.

\begin{tabular}{|c|c|c|c|c|c|c|c|c|}
\hline \multirow{4}{*}{$\begin{array}{c}\text { Conc } \\
(\mu \mathrm{g} / \mathrm{mL})\end{array}$} & \multicolumn{8}{|c|}{ Absorptivity, A (1\%, 1cm) } \\
\hline & \multicolumn{4}{|c|}{ Method A } & \multicolumn{4}{|c|}{ Method B } \\
\hline & \multicolumn{2}{|c|}{ CPX } & \multicolumn{2}{|c|}{ TNZ } & \multicolumn{2}{|c|}{ CPX } & \multicolumn{2}{|c|}{ TNZ } \\
\hline & $271 \mathrm{~nm}$ & $318 \mathrm{~nm}$ & $271 \mathrm{~nm}$ & 318nm & 292nm & 271nm & 292nm & 271nm \\
\hline 10 & 944.6 & 340.5 & 120 & 372.5 & 217 & 943.6 & 217 & 120 \\
\hline 15 & 956.67 & 339.87 & - & - & 201 & 955.66 & - & - \\
\hline 20 & 926.05 & 335.45 & 113.6 & 360.8 & 203.15 & 926.05 & 200.5 & 113.6 \\
\hline 25 & 910.04 & 330.6 & - & - & 201.32 & 910.04 & - & - \\
\hline 30 & 905.1 & 341.67 & - & - & 202.6 & 905.1 & - & - \\
\hline 35 & 899.31 & 343.51 & - & - & 202.4 & 899.31 & - & - \\
\hline 40 & - & - & 103.65 & 368.25 & - & - & 204.53 & 103.6 \\
\hline 60 & - & - & 103.18 & 374.5 & - & - & 198.5 & 103.1 \\
\hline 80 & - & - & 98.6 & 360.39 & - & - & 192.5 & 98.6 \\
\hline Mean & 923.63 & 338.59 & 107.81 & 367.29 & 204.5783 & 924.62 & 202.605 & 107.81 \\
\hline
\end{tabular}

Table 2: Results of simultaneous estimation of marketed formulation (Ciplox-Tz) for Methods A \& B.

\begin{tabular}{ccccccc}
\hline \multirow{2}{*}{ Method } & \multicolumn{2}{c}{ Label claim $(\mathbf{m g} /$ tablet) } & *Amount obtained $(\mathbf{m g} /$ tablet) & \multicolumn{2}{c}{${ }^{*} \operatorname{Recovery}(\%) \pm$ SD } \\
\cline { 2 - 7 } & CPX & TNZ & CPX & TNZ & CPX & TNZ \\
\hline Method A & 500 & 600 & 494.5 & 598 & $98.9 \pm 0.25$ & $99.8 \pm 0.27$ \\
Method B & 500 & 600 & 496 & 602.4 & $99.4 \pm 0.21$ & $100.4 \pm 0.18$ \\
\hline
\end{tabular}

${ }^{*}$ Mean of six estimations; $\mathrm{CPX}=$ Ciprofloxacin; TNZ = Tinidazole

Table 3: Regression analysis of calibration curves and summary of validation parameters for Methods A \& B.

\begin{tabular}{|c|c|c|c|c|c|c|}
\hline \multirow{2}{*}{$\begin{array}{l}\text { Sl. } \\
\text { No. }\end{array}$} & \multirow{2}{*}{ Parameter } & \multirow{2}{*}{ Drug } & \multicolumn{2}{|c|}{ Method A } & \multicolumn{2}{|c|}{ Method B } \\
\hline & & & $271 \mathrm{~nm}$ & 318nm & 292nm & 271nm \\
\hline \multirow{2}{*}{1} & \multirow{2}{*}{ Beer's law limit $\left(\mu \mathrm{g} \mathrm{ml}^{-1}\right)$} & CPX & \multirow{2}{*}{\multicolumn{4}{|c|}{$\begin{array}{r}10-35 \\
10-80\end{array}$}} \\
\hline & & TNZ & & & & \\
\hline \multirow{2}{*}{2} & \multirow{2}{*}{ Molar absorptivity $\left(\mathrm{mol}^{-1} \mathrm{~cm}^{-1}\right)$} & CPX & 30614 & 11223 & 6779 & 30614 \\
\hline & & TNZ & 2666 & 9082 & 5010 & 2666 \\
\hline \multirow{2}{*}{3} & \multirow{2}{*}{ Sandell's sensitivity $\left(\mu \mathrm{g} / \mathrm{cm}^{2} / 0.001\right)$} & $\mathrm{CPX}$ & 0.01 & 0.029 & 0.046 & 0.01 \\
\hline & & TNZ & 0.083 & 0.026 & 0.05 & 0.91 \\
\hline \multirow{2}{*}{4} & \multirow{2}{*}{ Intercept(c) } & $\mathrm{CPX}$ & 0.0418 & 0.004 & 0.004 & 0.041 \\
\hline & & TNZ & 0.018 & 0.0071 & 0.018 & 0.018 \\
\hline \multirow{2}{*}{5} & \multirow{2}{*}{ Slope (m) } & $\mathrm{CPX}$ & 0.0895 & 0.034 & 0.020 & 0.089 \\
\hline & & TNZ & 0.09 & 0.0365 & 0.019 & 0.009 \\
\hline \multirow[b]{2}{*}{6} & \multirow{2}{*}{ Correlation coefficient $\left(\mathrm{r}^{2}\right)$} & CPX & 0.9992 & 0.999 & 0.999 & 0.999 \\
\hline & & TNZ & 0.998 & 0.9993 & 0.999 & 0.9989 \\
\hline
\end{tabular}

Table 4: Results for recovery studies.

\begin{tabular}{|c|c|c|c|c|c|c|c|c|c|c|c|c|}
\hline \multirow{3}{*}{$\begin{array}{l}\text { Level of } \\
\text { Recovery } \\
(\%)\end{array}$} & \multirow{2}{*}{\multicolumn{4}{|c|}{$\begin{array}{c}\text { Drug in tablet Drug added } \\
(\mu \mathrm{g})\end{array}$}} & \multicolumn{4}{|c|}{${ }^{*}$ Drugrecovered $(\mu \mathrm{g})$} & \multicolumn{4}{|c|}{${ }^{*} \operatorname{Recovery}(\%) \pm \mathrm{SD}$} \\
\hline & & & & & \multicolumn{2}{|c|}{ Method A } & \multicolumn{2}{|c|}{ Method B } & \multicolumn{2}{|c|}{ Method A } & \multicolumn{2}{|c|}{ Method B } \\
\hline & CPX & TNZ & CPX & TNZ & CPX & TNZ & CPX & TNZ & $\mathrm{CPX}$ & TNZ & $\mathrm{CPX}$ & TNZ \\
\hline 80 & 8 & 10 & 6.4 & 8 & 14.1 & 17.8 & 13.96 & 17.7 & $98.8 \pm 0.17$ & $99 \pm 0.13$ & $98 \pm 0.5$ & $98.9 \pm 1.3$ \\
\hline 100 & 8 & 10 & 8 & 10 & 15.7 & 19.8 & 15.6 & 19.5 & $98.9 \pm 0.18$ & $98.7 \pm 0.26$ & $98.7 \pm 0.15$ & $99.7 \pm 0.19$ \\
\hline 120 & 8 & 10 & 9.6 & 12 & 17.3 & 21.6 & 17.2 & 21.5 & $98.1 \pm 0.42$ & $98.3 \pm 0.45$ & $98.3 \pm 0.28$ & $98.3 \pm 1.01$ \\
\hline
\end{tabular}


Table 5: Results for precision studies.

\begin{tabular}{|c|c|c|c|c|c|c|c|c|c|c|}
\hline \multirow{3}{*}{$\begin{array}{l}\text { Sl. } \\
\text { No. }\end{array}$} & \multirow{2}{*}{\multicolumn{2}{|c|}{ Conc $(\mu \mathrm{g} / \mathrm{mL})$}} & \multicolumn{4}{|c|}{${ }^{*}$ Assay $(\%) \pm$ SD } & \multicolumn{4}{|c|}{ *RSD (\%) } \\
\hline & & & \multicolumn{2}{|c|}{ Method A } & \multicolumn{2}{|c|}{ Method B } & \multicolumn{2}{|c|}{ Method A } & \multicolumn{2}{|c|}{ Method B } \\
\hline & CPX & TNZ & CPX & TNZ & CPX & TNZ & CPX & TNZ & CPX & TNZ \\
\hline 1 & 8 & 10 & $98.7 \pm 0.23$ & $98.93 \pm 0.12$ & $98.26 \pm 0.64$ & $99.3 \pm 0.41$ & 0.26 & 0.12 & 0.65 & 0.41 \\
\hline 2 & 16 & 20 & $98.73 \pm 0.23$ & $99.26 \pm 0.23$ & $99.2 \pm 0.69$ & $98.7 \pm 0.26$ & 0.24 & 0.23 & 0.71 & 0.26 \\
\hline 3 & 32 & 40 & $98.83 \pm 0.57$ & $98.38 \pm 0.68$ & $98.2 \pm 0.69$ & $98.67 \pm 0.29$ & 0.59 & 0.69 & 0.75 & 0.29 \\
\hline
\end{tabular}

*Mean of three estimations; CPX = Ciprofloxacin; TNZ = Tinidazole

curves were plotted to verify the Beer's law and the absorptivity values calculated at the respective wavelengths for both the drugs. The absorptivity values are reported in Table 1.

The concentration of two drugs in mixture was calculated by using the following equations:

$C_{X}=\frac{Q_{m}-Q_{y}}{Q_{x}-Q_{y}} \times \frac{A_{1}}{a_{X 1}}$
$C_{Y}=\frac{Q_{m}-Q_{X}}{Q_{y}-Q_{x}} \times \frac{A_{1}}{a_{Y} 1}$

Where, $A_{1}$ and $A_{2}$ are the absorbances of mixture at 292nm and 271nm,ax1 (107.8), ax2 (367.3) and ay1 (924.6), ay2 (348.6) are A $(1 \%, 1 \mathrm{~cm})$ of TNZ and $\mathrm{CPX}$ at $292 \mathrm{~nm}$ and $271 \mathrm{~nm}$ respectively,

$\mathrm{Q}_{\mathrm{m}}=\mathrm{A}_{2} / \mathrm{A}_{1}, \mathrm{Q}_{\mathrm{x}}=\mathrm{ax}_{2} / \mathrm{ax}_{1}$ and $\mathrm{Q}_{\mathrm{y}}=\mathrm{ay}_{2} / \mathrm{ay}_{1}$

\section{Assay of tablets by Method A and B}

20 commercial tablets of CPX and TNZ were triturated and powder equivalent to $10 \mathrm{mg}$ of TNZ and $8.0 \mathrm{mg}$ of CPX respectively was weighed and transferred to $10 \mathrm{~mL}$ volumetric flask, dissolved in methanol, volume adjusted up to the mark with the same solvent and mixed well with the help of a sonicator. The solution was filtered through Whatman filter paper no $40.1 \mathrm{~mL}$ of the above filtrate was diluted to $10 \mathrm{~mL}$ with phosphate buffer to obtain a $100 \mu \mathrm{g} / \mathrm{mL}$ solution with respect to TNZ. From this solution an aliquot was taken and made up the volume to $10 \mathrm{~mL}$ with phosphate buffer expected to contain 10 and $8 \mu \mathrm{g} / \mathrm{mL}$ of CPX and TNZ respectively. The absorbance of the sample solution was measured at $271 \mathrm{~nm}$ and 318nm(Method A), 292nm and 271nm (Method B) and the data analyzed accordingly using the necessary equations. The analysis procedure was repeated for 6 times with tablet formulations. The result of analysis of tablet formulation is reported in Table 2.

\section{Validation (Method A\&B) \\ Linearity}

Appropriate dilutions of working standard solutions for CPX and TNZ were prepared in the concentration range of $10-35 \mu \mathrm{g} / \mathrm{mL}$ and $10-80 \mu \mathrm{g} / \mathrm{mL}$, respectively and analyzed as per the developed methods A \& B. The results are reported in Table 3.

\section{Accuracy and Recovery studies}

To check the accuracy of the proposed method, recovery studies were carried out by standard addition method at three different levels according to ICH guidelines. A series of solutions of CPX and TNZ at $80 \%, 100 \%$, and $120 \%$ of the standard preparation in the ratio of the formulation were prepared and checked for accuracy by determining the absorbance values at $\lambda_{\max }$ of $271 \mathrm{~nm}$ and $318 \mathrm{~nm}$ (Method A) 292nm and 271nm (method B) respectively. To a fixed concentration of the formulation, varying concentrations of pure drug solutions were added and percentage recoveries calculated. The result of the analysis is given in Table 4 .

\section{Precision}

Precision studies were performed at three different concentrations in the ratio of the formulation, each concentration prepared three times for CPX and TNZ together. The result of the analysis is given in Table 5 .

\section{RESULTS AND DISCUSSION}

Ciprofloxacin and Tinidazole exhibited maximum absorption at $271 \mathrm{~nm}$ and $318 \mathrm{~nm}$ (Method A), they were also analyzed at 292nm and 271nm (Method B). CPX obeyed Beer's law in the concentration range of $10-35 \mu \mathrm{g} / \mathrm{mL}$ while TNZ obeyed the Beer's law in the concentration range of $10-80 \mu \mathrm{g} / \mathrm{mL}$ (Method A \& B). The precision data shows that the reproducibility of the assay procedure was satisfactory. The recovery studies done by standard addition method has given satisfactory results with an average percentage recovery of $98.6 \%$ and $98.7 \%$ (Method A), 98.4\% and 99.0\% (Method B) for CPX and TNZ respectively. The regression analysis of the calibration curves and the optical characteristics 
such as Beer's law limits, molar absorptivities and Sandell's sensitivities were also determined. The results shown in Table 3.

\section{CONCLUSION}

Two new, simple, sensitive and economical UV spectrophotometric methods were developed for the simultaneous analysis of Ciprofloxacin and Tinidazole in bulk and in pharmaceutical formulations. The developed methods were validated and from the statistical data, it was found that the methods were linear, accurate and precise and can be successfully applied for the analysis of pharmaceutical formulations without interference of excipients.

\section{ACKNOWLEDGEMENT}

The authors are grateful to M/s Gitam Institute of Pharmacy, Gitam University, and Visakhapatnam for providing necessary facilities.

\section{REFERENCES}

Beckett, A.H., Stenlake, J.B (2005) Practical pharmaceutical chemistry, (4 ${ }^{\text {th }}$ ed., part II, pp.286) CBS publishers, New Delhi.

Bhatia, M.S., Kaskhedikar, S.G., Chaturvedi, S.C (1999) High performance liquid chromatographic estimation of Ciprofloxacin hydrochloride and Tinidazole from tablets.Indian Journal of Pharmaceutical Sciences,61(5), 311-312.

Bombale, M.V., Kadam, S.S., Dhaneshwar, S.R (1997) Simultaneous spectrophotometric estimation of Ciprofloxacin and Tinidazole from a combined dosage form. Indian Journal of Pharmaceutical Sciences, 59(5), 265-8.

Drlica, K., Zhao, X.K (1997) DNA gyrase, topoisomerase IV, and the 4-quinolones . Microbiol Mol Biol Rev, 61(3), 377392.

Nijhu, R.S., Akhter, D.S., Jhanker, Y.M (2011) Development and validation of UV spectrophotometric method for quantitative estimation of Nitroglycerin in pharmaceutical dosage form. International Current Pharmaceutical Journal, 1(1), 1-5. [DOI]

Salvi, V.S., Sathe, P.A., Rege,P.V (2010) Determination of Tinidazole and Ciprofloxacin Hydrochloride in Single Formulation Tablet using Differential Pulse Polarography .Journal of Analytical \&Bio analyticalTechniques, 1(3). [DOI]

Sharma, R., Pathodiya, G., Mishra, P.G., Sainy, J. (2011) A novel spectrophotometric method for quantitative determination of Ciprofloxacin hydrochloride and Tinidazole in tablets using hydrotropic solubilizing agent. Journal of Pharmacy Research, 4(3), 859-861.

The Merck Index, (2006) $14^{\text {th }}$ ed., pp.386, 1624, Merck \& Co., INC., Whitehouse station, NJ. 